\title{
Política de defesa nacional do Brasil: uma política de Estado ou de governo?
}

\author{
Brazil's national defense policy: \\ a State or government policy?
}

\section{LEANDRO WOLPERT DOS SANTOS}

\section{INTRODUÇÃO}

Parte da literatura vigente no Brasil propõe-se a analisar a política de defesa nacional como uma política pública (Proença Jr. and Duarte 2003; Oliveira 2006; Alsina Jr. 2003; 2009; Almeida 2010; Rudzit and Casarões 2015). Todavia, parece não haver consenso entre os analistas quanto à natureza desta política pública: seria a defesa nacional uma política pública de Estado ou de governo?

Segundo Almeida (2010, 241), políticas públicas caracterizam-se por serem políticas de longo prazo, sendo esta a principal razão pela qual a defesa nacional, detentora de objetivos permanentes, constitui uma política de Estado e não "simples planos de governo". Assim, na visão do autor, a condução da política de defesa nacional deve estar imune às rivalidades domésticas e mudanças de governo. À semelhança de Almeida (2010), Oliveira (2006) argumenta que a condição de política pública da defesa nacional confere a ela natureza de política de Estado, em que se pressupõe um arranjo conceitual e político subjacente, acordado por militares, diplomatas, partidos políticos e sociedade civil, sobre as ameaças, objetivos e recursos da defesa nacional. Nesse sentido, a política de defesa nacional deve mostrar-se incólume às disputas partidárias entre a situação e a oposição, de maneira que o permanente reexame dos seus conceitos esteja em sintonia com as injunções do contexto internacional.

Leandro Wolpert dos Santos - Doutorando em Ciência Política no Instituto de Estudos Sociais e Políticos (IESP/UERJ). Pesquisador do NEAAPE (Núcleo de Estudos Atores e Agendas de Política Externa), OPSA (Observatório Político Sul-Americano) e GAPE (Grupo de Análise de Política Externa). Bolsista CNPq. 
No sentido oposto ao de Almeida (2010), Oliveira (2006), autores como Proença Jr. e Duarte (2003) e Rudzit e Casarões (2015) postulam que tratar a política de defesa nacional como política pública implica considerar, necessariamente, a dinâmica de seu processo decisório, sobre o qual incidem, além dos constrangimentos sistêmicos, as injunções próprias da política doméstica, caracterizadas pelas disputas partidárias/ideológicas e por conflitos entre grupos de interesse. Nessa perspectiva, a política de defesa, assim como outras políticas públicas, é resultado ou reflexo da correlação de forças políticas internas em um determinado momento, encontrando-se sujeita, pois, a oscilações de conteúdo e escopo conforme mudanças de governo no plano doméstico. Esta é a razão pela qual Rudzit e Casarões (2015) asseveram que, em contextos democráticos, a política de defesa é política de governo e não política de Estado.

É nesse debate acadêmico que se insere o objeto de estudo do presente artigo. Nele, defendemos a hipótese de que a política de defesa nacional do Brasil possui características de política de Estado, dada a continuidade no tempo de seus principais objetivos e estratégias, mas também de governo, com espaço para a introdução de inovações conceituais e mudanças de ênfase diante de alterações de governo. Para fundamentar nossa hipótese, empreendemos dois tipos de comparações. $\mathrm{Na}$ primeira, são cotejadas as políticas de defesa nacional dos governos Cardoso (1995-2002) e Lula (2003-2010), com o intuito de identificar os elementos de continuidade e mudança no período em exame. Para tanto, são analisados documentos oficiais relacionados à defesa, tais como a Política de Defesa Nacional de 1996 e 2005, a Estratégia Nacional de Defesa END/2008 e alguns dos programas plurianuais elaborados em ambos os governos. A segunda comparação é feita entre as principais ideias em matéria de defesa nacional presentes nos programas de governo do PT e PSDB entre 1994 e 2006. Com essa comparação, busca-se aferir se existe consenso ou predominam divergências entre estes partidos, e se as convergências e divergências partidárias coincidem com as continuidades e mudanças identificadas na política de defesa nacional do governo Lula em comparação à administração Cardoso. As comparações são realizadas utilizando-se como parâmetro de referência alguns dos elementos primordiais que, consoante Rudzit e Nogami (2010), compõem uma política de defesa nacional, quais sejam: i) definição dos interesses nacionais, pelos quais o país estaria disposto a, em última instância, recorrer à guerra; ii) identificação das ameaças; iii) delimitação dos objetivos de defesa; e iv) estabelecimento de estratégia de defesa. 


\section{A POLÍTICA DE DEFESA NACIONAL NOS GOVERNOS CARDOSO E LULA (1995-2002/2003-2010)}

\section{Definição dos interesses nacionais}

Nos governos Cardoso e Lula, a defesa da Amazônia e do Atlântico Sul configurou a prioridade estratégica da política de defesa brasileira. Em 1996, a PDN, ao antever o possível envolvimento do Brasil em um conflito gerado externamente caso este implicasse em ameaça ao patrimônio brasileiro, fazia menção especial aos interesses do país localizados na Amazônia, que poderiam vir a ser contrariados pela atuação de bandos armados no entorno regional (Brasil 1996a). O plano plurianual 2000-2003, elaborado no governo Cardoso, de igual modo realçava a importância de "forças suficientemente preparadas para gerar a dissuasão eficaz" com vistas a defender as "grandes dimensões do território" e o "imenso patrimônio de recursos naturais ainda não explorados" do Brasil. Nele, o governo dava ênfase às atividades de defesa da Amazônia, onde a presença do Estado deveria ser ampliada e consolidada, e a vigilância nas fronteiras mais remotas, intensificada (Brasil 2000a, 13). A prioridade estratégica concedida à Amazônia também aparecia no plano plurianual 1996-1999 bem como em mensagens presidenciais enviadas ao Congresso Nacional (Brasil 1996b; 1998; 2001).

Ao Atlântico Sul, foi dada menor ênfase nos documentos da política de defesa de Cardoso. Mesmo assim, a região configurava, ao lado da América do Sul (Amazônia), um espaço privilegiado (Vaz 2013). De fato, no plano plurianual 1996-1999, a promoção da cobertura total da fronteira leste do Brasil, estendida, a partir da Convenção das Nações Unidas sobre o Direito do Mar, com a incorporação de mais de 4,5 milhões de $\mathrm{km}^{2}$ da Plataforma Continental Brasileira, figurava entre um dos principais objetivos do governo neste período (Brasil 1996b). Na PDN de 1996, o Atlântico Sul foi concebido, junto com a massa continental sul-americana, como parte do entorno regional brasileiro, de onde também se subentende que as preocupações e interesses brasileiros em matéria de defesa abarcavam esse espaço geográfico no período (Brasil 1996a). Em 2000, mencionava-se o Atlântico Sul, ao lado da Amazônia, como área de atuação privilegiada nos planos estratégicos das três forças singulares (Brasil 200ob).

No governo Lula, a PDN de 2005 indicava claramente a Amazônia e o Atlântico Sul como prioridades estratégicas do Brasil, devido a sua riqueza de recursos e vulnerabilidade de acesso externo pelas fronteiras terrestre e marítima. O documento apontava a Amazônia brasileira como foco da atenção internacional, dado seu grande potencial de riquezas minerais e de biodiversidade, e via com apreensão a prática de crimes transnacionais 
e a presença de grupos contrários aos interesses nacionais na região. $\mathrm{O}$ Atlântico Sul, tido como a "Amazônia Azul", de igual modo era considerado uma região de vital importância para o país, com as maiores reservas nacionais de petróleo e gás, elevado potencial pesqueiro e movimentação de quase a totalidade do comércio exterior brasileiro (Brasil 2005).

A PDN de 2005 inovou em relação à PDN de 1996 ao introduzir o termo entorno estratégico brasileiro para designar o espaço geográfico conformado pela massa continental sul-americana e o Atlântico Sul, onde residiriam as prioridades estratégicas da política de defesa brasileira. Mais do que isso, o documento incluía, nessa região, os países lindeiros da África Ocidental. Por essa razão, além dos países da América do Sul, a PDN de 2005 atribuía prioridade aos países da África, em especial aos da África Austral e aos de língua portuguesa, com quem propunha aprofundar os laços de amizade (Brasil 2005).

Na END de 2008, a Amazônia também figurava como "um dos focos de maior interesse para a defesa” no Brasil. Ao estabelecer como diretriz a priorização da região amazônica, a END garantia que o Brasil seria "vigilante na reafirmação incondicional de sua soberania sobre a Amazônia brasileira"; "repudiaria, pela prática de atos de desenvolvimento e de defesa, qualquer tentativa de tutela sobre as suas decisões a respeito de preservação, de desenvolvimento e de defesa da Amazônia”; e não permitiria que organizações ou indivíduos servissem de "instrumentos para interesses estrangeiros - políticos ou econômicos - que queiram enfraquecer a soberania brasileira". Ao final, o documento sacramentava que "quem cuida da Amazônia brasileira, a serviço da humanidade e de si mesmo, é o Brasil” (Brasil 2008a, 4).

A importância estratégica da Amazônia e do Atlântico Sul igualmente é reforçada nas hipóteses de emprego das Forças Armadas da END de 2008, entre as quais se encontram: i) a ameaça de penetração nas fronteiras terrestres ou abordagem nas águas jurisdicionais brasileiras; ii) a ameaça de forças militares muito superiores na região amazônica; e iii) a ameaça de conflito armado no Atlântico Sul (Brasil 2008a).

Do exposto acima, deduz-se que os interesses nacionais pelos quais o Brasil estaria disposto a entrar em guerra, em essência, permaneceram os mesmos na política de defesa dos governos Cardoso e Lula, ou seja, a proteção da soberania e dos recursos naturais da região amazônica e do Atlântico Sul. As diferenças incidiram, sobretudo, na concepção do entorno estratégico brasileiro que, na administração petista, passou a abarcar, além do subcontinente sul-americano e o Atlântico Sul, os países costeiros da África Ocidental. 


\section{Identificação de ameaças}

As políticas de defesa de Cardoso e Lula não identificavam inimigos específicos nem ameaças militares bem definidas aos interesses nacionais brasileiros. A imprecisão no diagnóstico de ameaças se justificava na leitura feita do cenário internacional pós-Guerra Fria, assinalado pela baixa probabilidade de um conflito generalizado entre os Estados, mas, por outro lado, despojado de previsibilidade estratégica e com elevado grau de incerteza. O entorno regional sul-americano, por sua vez, era visto como uma zona relativamente pacífica, graças a um conjunto de fatores, tais como a distância geográfica dos focos mundiais de tensão, seu reduzido nível de militarização, o processo de consolidação democrática no subcontinente e a presença de diversas iniciativas de integração regional (Brasil 1996a; 2005).

Contudo, existiam diferenças entre os governos Cardoso e Lula quanto ao escopo e ênfase dos riscos percebidos na ordem e segurança internacionais, reforçando, assim, a necessidade do cultivo de forças nacionais de defesa. Na leitura do ambiente internacional feito pela PDN de 1996, eram apontados os riscos representados pelo recrudescimento de extremismos étnicos, nacionalistas e religiosos, bem como pelo fenômeno da fragmentação de Estados. No entorno regional, como já comentado acima, eram mencionadas as zonas de instabilidade nos países vizinhos que poderiam contrariar os interesses brasileiros, com destaque para a ação de bandos armados e o crime organizado nas fronteiras da Amazônia (Brasil 1996a). Nesse sentido, a crise securitária na Colômbia causava particular apreensão (Brasil 2001). No governo Lula, a PDN reiterava as fontes potenciais de conflito e instabilidade internacionais identificadas na administração Cardoso, mas incluía outras, a saber: i) o incremento potencial das disputas por fronteiras terrestres e áreas marítimas, pelo domínio aeroespacial e por fontes de água doce e de energia, cada vez mais escassas; ii) a crescente exclusão de parcela significativa da população mundial dos processos de produção, consumo e acesso à informação; iii) a unipolaridade da ordem mundial no campo militar, associada às assimetrias de poder; iv) o interesse internacional despertado pelas reservas de recursos naturais nos países detentores de grande biodiversidade; v) a vulnerabilidade externa diante dos avanços da tecnologia da informação nos países com altos gastos em defesa que podem comprometer o sistema nacional de defesa e facilitar a interferência à distância (ataque cibernético); e vi) e terrorismo internacional (Brasil 2005).

Ao fazer referência à unipolaridade da ordem mundial, às assimetrias de poder e à desigualdade de avanço tecnológico entre os Estados — podendo ser acrescentado também o interesse internacional despertado pelos países 
detentores de grande biodiversidade - como fontes potenciais de ameaça, a PDN de 2005 sugeria, ainda que sutilmente, a possibilidade do surgimento de tensões com os países avançados, em especial os do hemisfério ocidental. Essa impressão é reforçada pela END de 2008, que previa o preparo para uma "guerra assimétrica" em defesa da Amazônia, "a ser sustentada contra inimigo de poder militar muito superior, por ação de um país ou de uma coligação de países que insista em contestar, a pretexto de supostos interesses da Humanidade, a incondicional soberania brasileira sobre a sua Amazônia" (Brasil 2008a, 10). Desse modo, tanto a PDN quanto a END parecem, em alguma medida, ter renovado a atenção, no governo Lula, para o risco potencial representado pelas ameaças tradicionais, ou seja, a competição interestatal, o que, na política de defesa de Cardoso, foi menos enfatizada se comparado com as ameaças não-convencionais, em especial o crime transnacional.

Por último, cabe dizer que as principais ameaças identificadas nos governos Cardoso e Lula eram de natureza externa (Brasil 1996a; 2005; 2008a). Isso não impediu, contudo, que, sob o comando de ambos os governantes, as Forças Armadas brasileiras fossem empregadas de maneira recorrente na provisão de segurança pública, as chamadas operações de Garantia da Lei e da Ordem (GLO). Na gestão tucana, os militares foram amplamente utilizados em apoio às forças policiais na contenção de movimentos sociais, especialmente de greves operárias e protestos campesinos, estes capitaneados, sobretudo, pelos militantes do MST (Movimento dos Trabalhadores Rurais Sem Terra) (Martins Filho 2000). De acordo com Saint-Pierre e Winand (2003), ainda no final do governo Cardoso, foi solicitada a presença das Forças Armadas no reforço do policiamento das eleições de 2002, contra a possível ação de criminosos que pretendiam tumultuar o processo eleitoral. Já no governo Lula, não foi rara a participação dos militares brasileiros no desempenho de funções policiais tradicionais na segurança pública do Estado do Rio de Janeiro. Expressão máxima dessa participação ocorreu em 2010, quando o Ministério da Defesa, sob a liderança de Nelson Jobim, assinou um acordo com o governador do Rio de Janeiro, pelo qual se criou uma Força de Pacificação (FPaz) nos Complexos Alemão-Penha, inspirada nos logros da Missão das Nações Unidas para a estabilização no Haiti (MINUSTAH) (Lima 2015).

\section{Objetivos de Defesa}

Segundo os documentos de defesa, os planos plurianuais e as mensagens presidenciais analisados nestes artigo, os principais objetivos (e/ou diretrizes) da política de defesa brasileira no governo Cardoso permaneceram os mesmos no governo Lula. Entre os quais figuram: i) a garantia da soberania, 
do patrimônio nacional e da integridade territorial; ii) a preservação da coesão e da unidade nacionais; iii) a defesa dos interesses brasileiros no exterior e a salvaguarda das pessoas, dos bens e dos recursos brasileiros ou sob a jurisdição brasileira; iv) a projeção do Brasil no concerto das nações e sua maior inserção no processo decisório mundial; v) a participação brasileira nas operações internacionais de manutenção da paz; ${ }^{1}$ vi) a promoção da estabilidade e da integração regional; vii) a participação das Forças Armadas em ações subsidiárias ao desenvolvimento socioeconômico do país, à defesa civil e à integração nacional; viii) a modernização e o aprimoramento da organização, do aparelhamento, do adestramento e da articulação das Forças Armadas; ix) o fomento de pesquisas científicas e o desenvolvimento de projetos tecnológicos e de capacidade de produção, visando minimizar a dependência tecnológica externa do país quanto aos recursos de natureza estratégica; $x$ ) a revigoração da indústria bélica nacional; xi) a promoção do conhecimento científico da região antártica e a participação ativa no processo decisório do seu destino; e xii) a conscientização da sociedade sobre os assuntos de defesa (Brasil 1996a; 1996b; 1998; 2000a; 2005; 2008b).

No governo Lula, alguns objetivos importantes foram introduzidos na PDN de 2005, tais como: i) o aperfeiçoamento dos dispositivos e procedimentos de segurança que reduzam a vulnerabilidade dos sistemas relacionados à Defesa Nacional contra ataques cibernéticos; ii) a disposição de uma estrutura capaz de contribuir para a prevenção de atos terroristas e de conduzir operações de contraterrorismo; iii) o aumento da presença militar no Atlântico Sul; e iv) o fomento da integração regional no desenvolvimento da base industrial de defesa (Brasil 2005).

Não obstante o importante passo dado por Cardoso na sujeição dos militares ao poder civil e na racionalização da gestão da política de defesa sobretudo no tocante à representatividade internacional do país - com a criação do Ministério da Defesa em 1999, pode-se afirmar, de modo geral, que os objetos de defesa nacional e o próprio tema da defesa ganharam mais espaço na agenda política brasileira durante o governo Lula, particularmente em seu segundo mandato (Beertonha 2010; Boreli and Peron 2017). Os esforços despendidos na organização e orientação das Forças Armadas brasileiras, por meio da elaboração da END em 2008, assim como o maior volume de recursos públicos orçamentários destinados à área, podem ser vistos como evidências nesse sentido (ver Gráfico 1). ${ }^{2}$ Além do aumento dos gastos públicos em defesa, houve, no governo Lula, um esforço adicional para que esses gastos fossem direcionados para o incremento dos investimentos públicos em defesa - que passou de $\mathrm{R} \$ 4,5$ bilhões, no final da administração Cardoso, para R $\$ 12$ bilhões, em 2010 -, muito embora a essência da estrutura orçamentária da política brasileira de defesa 
tenha se mantido a mesma, com a maioria dos recursos sendo destinados às despesas com pessoal (Gráfico 2).

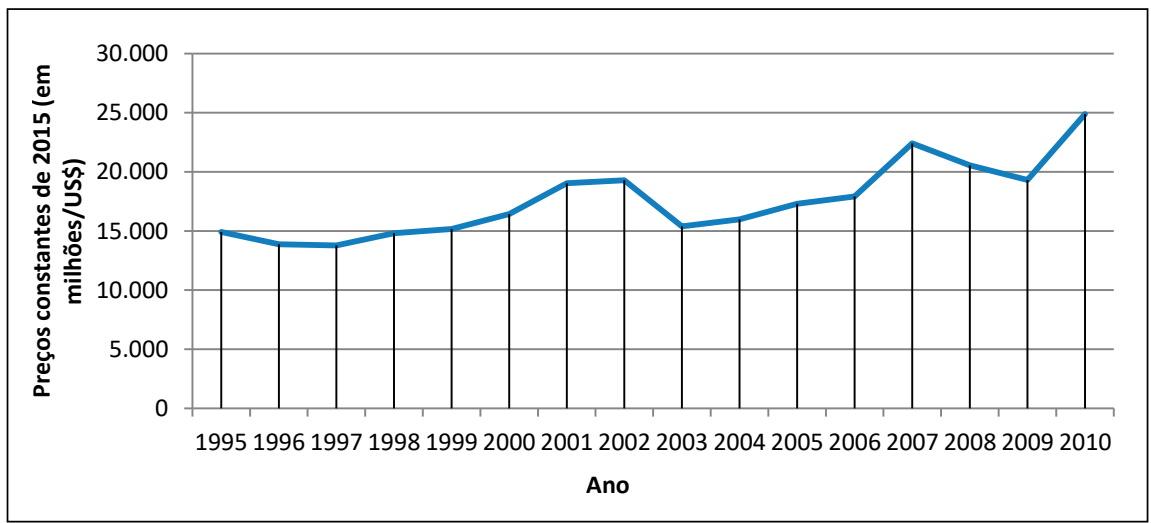

Gráfico 1 - Gastos públicos em defesa a preços constantes de 2015 (em milhões/US\$). Fontes: SIPRI databases. Elaboração própria.

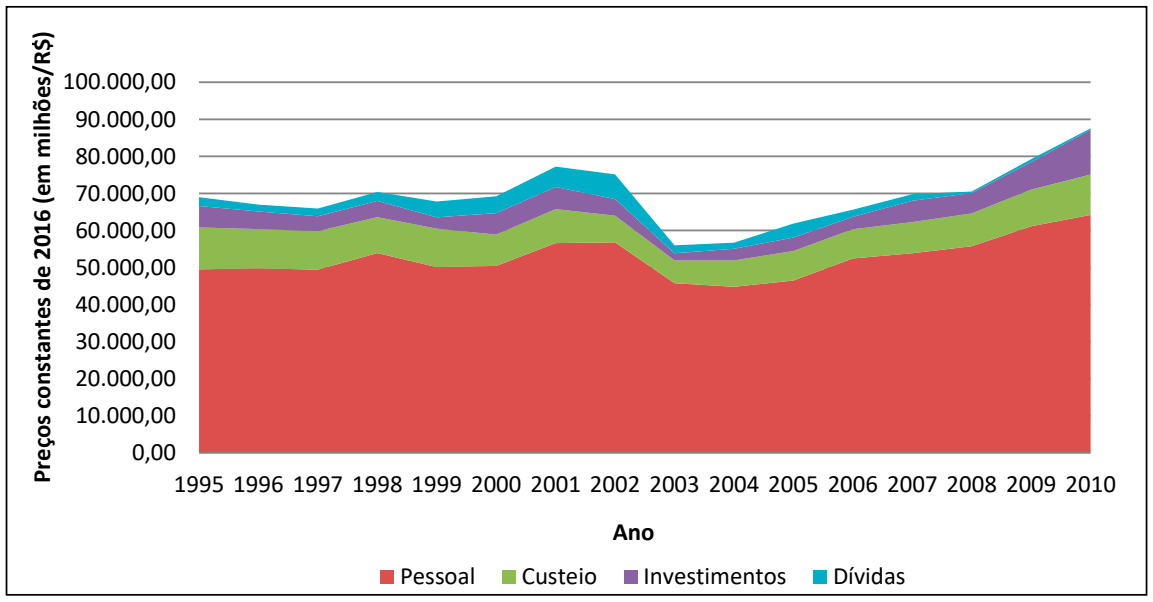

Gráfico 2 - Estrutura orçamentária dos gastos públicos em defesa a preços constantes de 2016 (em milhões $/ \mathrm{R} \$$ ).

Fontes: SEORI. Elaboração própria.

Desse modo, o aumento dos gastos em defesa no governo Lula forneceu as condições materiais para que se ampliassem os efetivos militares das Forças Armadas brasileiras, de 287.600, em 2002, para 327.710, em 
2010. ${ }^{3}$ Viabilizou, igualmente, melhor reaparelhamento e modernização do Exército, da Marinha e da Aeronáutica, com destaque especial para o projeto de construção do submarino de propulsão nuclear brasileiro, retomado em 2008 (Bertonha 2010). Permitiu ainda que o Brasil incrementasse sua participação nas missões internacionais de paz patrocinadas pelas Nações Unidas, ao assumir, desde 2004, a liderança do comando militar da MINUSTAH, ${ }^{4}$ bem como fomentasse maior intervenção estatal na alavancagem do setor produtivo nacional de material de defesa por meio de incentivos fiscais e fornecimento de crédito. ${ }^{5}$

Todavia, as mudanças mais importantes nos objetivos da política de defesa de Lula aparecem na intersecção da defesa com a diplomacia. No que tange à cooperação internacional em matéria de defesa, por exemplo, os acordos firmados no governo Lula com países em desenvolvimento não só foram mais numerosos em relação à administração Cardoso, como também corresponderam à grande maioria do total dos acordos firmados no período. ${ }^{6}$ De fato, como propugnado nas diretrizes da PDN de 2005, os laços de amizade com os países sul-americanos e do continente africano foram reforçados (Brasil 2005). Em acréscimo, no governo de Lula, a cooperação internacional em matéria de defesa foi qualificada por dois critérios: i) transferência de tecnologia; e ii) busca por maior pluralismo de poder e de visão na política mundial com vistas a promover a reestruturação das organizações internacionais, em especial aquelas nascidas ao término da Segunda Guerra Mundial, e melhorar a representação de países emergentes, inclusive do Brasil, no processo decisório internacional (Brasil 2008a).

No que diz respeito o primeiro critério, são emblemáticos os acordos de transferência de tecnologia firmados pelo Brasil com a França em 2008, para a construção de quatro submarinos convencionais e um submarino de propulsão nuclear, e com a Ucrânia em 2003, que resultou na criação, três anos depois, de uma empresa binacional para o lançamento de foguetes e satélites a partir do Centro de Lançamento de Alcântara (CLA), localizado no Estado do Maranhão. Rompido em 2015, este acordo era visto pelas autoridades brasileiras, em 2003, como alternativa ao Acordo sobre Salvaguardas Tecnológicas Brasil-Estados Unidos para o uso comercial do CLA, o qual impedia a transferência de tecnologia para o programa brasileiro de veículos de lançamento espacial.

Vale lembrar que o Tratado sobre Salvaguardas Brasil-EUA, assinado em 2001, partiu da iniciativa do presidente Fernando Henrique Cardoso, mas não foi ratificado, devido à falta de consenso entre as diferentes comissões da Câmara dos Deputados do Congresso brasileiro (Camino and Menck 2016). Além de barrar qualquer tipo de compartilhamento de tecnologia entre os Estados Unidos e o Brasil, o acordo de salvaguardas pos- 
suía cláusulas, nomeadas como "salvaguardas políticas", que restringiam a autonomia da política externa e de defesa brasileiras. Por essa razão, tornaram-se o principal alvo das críticas feitas, sobretudo, por parte dos partidos e congressistas de oposição a Cardoso, com destaque para o deputado petista Waldir Pires, que viria a se tornar Ministro da Defesa do governo Lula em 2006. O Tratado de Salvaguardas Brasil-EUA, de igual modo, foi condenado por integrantes da sociedade civil, que expressaram seu rechaço através do plebiscito popular sobre a ALCA (Área de Livre Comércio das Américas), convocado, em 2002, por movimentos populares, sindicais e estudantis, com o apoio da Conferência Nacional dos Bispos do Brasil (CNBB). Em 2003, quando Lula já era presidente, chegou-se a comemorar o arquivamento do texto do acordo e sua retirada de pauta da Câmara dos Deputados, muito embora o procedimento formal só tenha se concretizado efetivamente mais de dez anos depois (Camino and Menck 2016).

O segundo critério qualificador da política de defesa de Lula para cooperação internacional, do qual a parceria estratégica com a França e o acordo de Alcântara com os EUA também são representativos, está relacionado com o objetivo velado da política externa petista de balanceamento brando do poder e da ordem hegemônica estadunidense (Hurrel 2006; Bertonha 2010). É preciso lembrar que a END de 2008, muita embora não se refira explicitamente aos Estados Unidos, menciona a unipolaridade da ordem mundial como fonte potencial de instabilidade internacional. Ora, no período da elaboração da END, nenhuma outra potência mundial, que não os Estados Unidos, poderia almejar essa posição. Destarte, ao combinar a percepção da unipolaridade e da assimetria de poder como potenciais de ameaça com a associação do estabelecimento de parcerias estratégicas à "busca por maior pluralismo de poder e visão no mundo", em outras palavras, à multipolaridade, a END sugeria, indiretamente, a contenção da primazia estadunidense, ainda que não por meios militares nem através da confrontação direta ou uso da força, muito menos com a exclusão da boa convivência com os EUA (Bertonha 2013).

A consubstanciação da integração regional em defesa, preconizada pela PDN e END, através da criação, em 2008, sob a iniciativa brasileira, do Conselho de Defesa Sul-Americano (CDS), no âmbito da União das Nações Sul-Americanas (UNASUL), parece também comportar a lógica do balanceamento brando, porquanto, além de propugnar o fortalecimento de uma identidade comum sul-americana em defesa e contribuir para a redução da dependência tecnológica externa, o CDS, sem constituir efetivamente uma aliança militar, permite que os contenciosos entre os países sul-americanos sejam resolvidos regionalmente, sem a interferência externa de forças alienígenas, tais como a OEA (Vaz 2013; Teixeira Júnior and Silva 2017). ${ }^{7}$ 


\section{Estratégia de Defesa}

Diferentemente de Lula, Cardoso não chegou a elaborar um documento específico para tratar da estratégia nacional de defesa. Mesmo assim, é possível depreender da PDN de 1996 os principais elementos da concepção estratégica do governo psdebista e, dessa maneira, compará-los com a estratégia do governo petista. Senão vejamos.

As orientações estratégicas das políticas de defesa de Cardoso e Lula compartilhavam as mesmas premissas centrais: i) rejeição à guerra de conquista; ii) busca de solução pacífica de controvérsias; e iii) estreito relacionamento com os países vizinhos e com a comunidade internacional. As respectivas orientações também eram compostas por duas vertentes iguais: uma preventiva, baseada na valorização da ação diplomática e na capacitação do poder militar dissuasório; outra reativa, no caso de ocorrer uma agressão armada ao país, situação na qual previa-se o emprego de todo o poderio militar necessário com vistas a repelir a ameaça (Brasil 1996a; 2005).

Como visto, a defesa da Amazônia e do Atlântico Sul consistia na prioridade estratégica de ambos os governos. Para lográ-la, concebia-se uma série de ações estratégicas. No caso da Amazônia, propunha-se o fortalecimento da presença militar, a efetiva ação do Estado no desenvolvimento socioeconômico e a ampliação da cooperação com os países vizinhos, visando o salvaguardo das riquezas naturais e do meio ambiente (Brasil 1996c; 2005). Nesse sentido, o Programa Calha Norte foi revigorado e ampliado nos governos Cardoso e Lula, respectivamente. Igual importância recebeu o programa SIVAM (Sistema de Vigilância da Amazônia) — SIPAM (Sistema de Proteção da Amazônia), cuja implantação, pela Aeronáutica, foi iniciada em 1997, para só entrar em funcionamento em 2002, tendo continuidade no governo Lula. Para a defesa do Atlântico Sul, os governos de Cardoso e Lula procuraram incrementar a capacidade de vigilância e controle das águas jurisdicionais brasileiras, por meio de investimentos no reaparelhamento da marinha e de sistemas de comunicação via satélites.

Em termos de capacidades militares, somente após anunciar a necessidade de revisão da política de defesa, ao final do segundo mandato, Cardoso estipulou os requerimentos logísticos e táticos que seriam necessários para o adestramento das Forças Armadas brasileiras, em havendo: capacidade de resposta rápida (mobilidade estratégica), versatilidade, flexibilidade, interoperabilidade e sustentabilidade (Brasil 2002; Proença Jr. and Duarte 2003). No governo Lula, houve um tratamento mais aperfeiçoado das capacidades militares e da organização das Forças Armadas brasileiras, sobretudo por meio da END 2008, que estipulou o trinômio monitoramento/ 
controle, mobilidade e presença como égide da orientação estratégica de defesa (END 2008).

A END 2008 trazia outra inovação, em comparação à política de defesa de Cardoso, ao resgatar um conceito característico do regime militar, empregado, sobretudo, no governo Geisel, a saber, o de projeção de poder. No documento, o referido conceito desponta tanto como objetivo estratégico a ser desempenhado pela Marinha, como uma das capacidades militares a serem alcançadas pelas Forças Armadas brasileiras nas suas áreas de interesse estratégico (Brasil 2008a). Essa inovação se alinha, pois, com a expansão do entorno estratégico brasileiro verificada na PDN de 2005, uma vez que indica o desejo do país de ampliar sua área de influência internacional no Atlântico Sul.

\section{A DEFESA NACIONAL NOS PROGRAMAS DE GOVERNO DO PT E PSDB ENTRE 1994 E 2006}

Na proposta de governo de Fernando Henrique Cardoso, em 1994, não há uma seção exclusiva para a discussão e apresentação de ideias na área da defesa nacional (na verdade, o termo defesa nacional sequer é mencionado). São pouquíssimas as referências relacionadas à temática, que aparecem de maneira dispersa nas seções de segurança pública, de política externa e no anexo do programa de governo. No documento, Cardoso promete não hesitar, se eleito, em fazer uso das Forças Armadas no combate ao crime, porém admite fazê-lo somente como último recurso, em situações realmente excepcionais e de maneira transitória, jamais para substituir permanentemente as forças policiais. Ainda de acordo com o documento, a verdadeira vocação e responsabilidade primordial das Forças Armadas é garantir a segurança e a tranquilidade das fronteiras, bem como afastar as ameaças à soberania nacional. Para cumprir essa função, Cardoso promete oferecer as condições necessárias para a modernização e o reaparelhamento das três forças singulares em consonância com as exigências do mundo contemporâneo, assim como promover a revalorização do profissionalismo militar, assegurando bom treinamento e devida renumeração. Nas diretrizes de política externa, encontram-se referências à participação brasileira em missões de paz da ONU e ao desenvolvimento de ações voltadas à repressão do narcotráfico e repúdio ao terrorismo (Cardoso 2008a).

Diferentemente do PSDB, o PT dedicou uma seção exclusiva de seu programa de governo de 1994 para as questões atinentes à defesa nacional. $\mathrm{Na}$ percepção do programa petista, inexistiam, naquele momento, ameaças perfeitamente caracterizadas aos interesses nacionais brasileiros que justificassem o emprego das Forças Armadas, de modo que a política de 
defesa no eventual governo Lula estaria subordinada aos objetivos do desenvolvimento e da democracia no país. Contudo, o programa identificava no eixo Norte-Sul as principais fontes de tensão do sistema internacional a partir dos anos 1980, em substituição ao eixo Leste-Oeste, característico do conflito bipolar. A Guerra das Malvinas, travada entre a Argentina e o Reino Unido em 1982, bem como a Guerra do Golfo em 1991, foram vistas como evidências desse novo contexto mundial. Outrossim, o fim da Guerra Fria, atrelado à redemocratização no Brasil, teria refutado a tese do inimigo interno, cabendo às Forças Armadas a defesa da soberania nacional de agressões externas. Nesse ponto, o documento é enfático ao propor uma reforma constitucional na qual a manutenção da ordem interna deveria ser retirada das atribuições das Forças Armadas. Destarte, partindo da convicção de que a democracia supõe o fim da tutela militar sobre a sociedade, o programa de governo petista fazia uma crítica ao pacto de transição firmado pelas elites civis e o setor castrense, que teria permitido a continuidade da não transparência de elementos-chave do poder militar no País. Em acréscimo, o programa defendia a maximização da autonomia estratégica do Brasil, com satisfatória capacidade dissuasória, nas relações mundiais de força, sobretudo no âmbito da América do Sul e no Atlântico Sul. Por fim, o documento ainda continha propostas para a criação de um ministério de defesa, a profissionalização e valorização dos quadros militares, o reaparelhamento progressivo da estrutura militar e a participação brasileira na solução pacífica de conflitos internacionais, sem, contudo, desrespeitar a soberania e os direitos humanos (PT 1994).

Em 1998, o programa de governo do PSDB decidiu reservar uma seção especial para a defesa nacional, expondo ideias e propostas um pouco mais claras sobre o tema. A modernização e o adestramento adequado das Forças Armadas foram vistos como essenciais para a proteção do território e do patrimônio de recursos naturais brasileiros. Em acréscimo, previa-se o emprego das três forças nos esforços para a manutenção da paz mundial, bem como na cooperação para a solução de crises internacionais, de sorte a projetar a imagem do Brasil no exterior. Alentava-se também o incremento da participação subsidiária dos militares nos programas de desenvolvimento nacional, nas operações de defesa civil e no salvaguardo do meio ambiente, sobretudo nas áreas mais inóspitas e carentes do país, onde a presença do Estado é mais rarefeita. Propunha-se, ainda, como incumbência dos militares, o apoio nas ações de combate ao narcotráfico e ao crime transfronteiriço. O programa definia o poder de dissuasão como o principal instrumento de defesa do Brasil, estipulando a proteção da Amazônia como prioridade estratégica. Finalmente, planejava-se a continuidade da implantação do Ministério da Defesa e o reaparelhamento das Forças Armadas 
com o objetivo de construir uma estrutura mínima compatível com a expressão geográfica e política do país (Cardoso 2008b).

Se, em 1994, o programa de governo petista possuía uma seção exclusiva para a defesa nacional, enquanto o programa do PSDB sequer mencionava o termo, em 1998, a equação se inverteu. Neste ano, a proposta de governo oficial do candidato Lula revelou-se bastante enxuta, com suas poucas páginas sendo dedicadas, em grande medida, a condenar a gestão de Fernando Henrique Cardoso como presidente da nação nos quatro anos anteriores. $\mathrm{O}$ documento não fazia menção alguma à defesa nacional nem às Forças Armadas (PT 1998).

Em 2002, o programa de governo psdebista reservou novamente uma seção exclusiva para os assuntos de defesa nacional. Nele, o então candidato a presidente da República José Serra propugnava que a afirmação dos valores democráticos frente às ameaças de guerra, de terrorismo e do crime transfronteiriço pautaria a política de defesa nacional de seu eventual governo. O programa reconhecia que a função primária das Forças Armadas é proteger a soberania e o território nacionais dos riscos externos, cabendo aos "Poderes constituídos" nos três níveis da Federação a responsabilidade pela estabilidade das instituições domésticas (PSDB 2002, 68). Entre as prioridades em matéria de defesa elencadas no documento, destacam-se as seguintes: i) consolidação das funções e estruturas do Ministério da Defesa; ii) ampliação das parcerias do Ministério da Defesa e das Forças Armadas com as universidades para a formação de recursos humanos civis e militares e o desenvolvimento de projetos científico-tecnológicos de interesse da defesa nacional; iii) ênfase na estratégia de presença na Amazônia, considerando os riscos derivados da situação colombiana; iv) reforço dos vínculos sub-regionais de cooperação militar na América do Sul, com destaque para o Mercosul (Mercado Comum do Sul), Pacto Andino e Amazônia; e v) renovação e modernização tecnológica dos instrumentos militares, inclusive com a participação dos centros de pesquisa e da indústria nacionais (PSDB 2002).

Na quarta campanha eleitoral de Lula à presidência da República, o PT seguiu destinando pouca atenção aos assuntos de defesa em seu programa de governo. Assim como em 1998, o programa de 2002 não destinava uma seção exclusiva para a política de defesa nacional, havendo apenas três parágrafos relacionados ao tema. Neles, o documento apontava o risco representado pelo crime organizado às instituições da defesa nacional, a crise de identidade vivenciada pelas Forças Armadas até então, as pressões nacionais e internacionais para que estas desempenhassem funções policiais e a escassez de recursos no setor. Para contornar esses problemas, o programa petista propunha um debate com o Congresso Nacional sobre o papel das 
Forças Armadas, a partir do qual seria possível definir o reequipamento militar e o redesenho da política de defesa nacional. Previa-se também: i) o emprego das Forças Armadas de acordo com sua missão constitucional, especialmente nas ações de defesa das fronteiras e proteção da integridade de regiões ameaçadas, com ênfase na Amazônia; ii) a participação dos militares brasileiros nas missões de paz no mundo; e iii) a modernização e o reforço das Forças Armadas do Brasil (PT 2002).

No programa de governo do PSDB de 2006, que sustentou a campanha do candidato Geraldo Alckmin, depreendem-se da seção dedicada à defesa nacional os seguintes objetivos das Forças Armadas: i) garantia da integridade territorial, do patrimônio, da soberania e dos interesses nacionais; ii) resguardo da integração e unidade nacionais; iii) fortalecimento da democracia; iv) combate aos crimes transnacionais; v) a garantia da lei e da ordem pública; e vi) colaboração em eventuais intervenções da ONU e da OEA (Organização dos Estados Americanos) em operações de manutenção de paz; Dava-se ênfase também ao "papel adicional” das Forças Armadas na provisão da segurança pública, em apoio às polícias federais e estaduais nas áreas de inteligência, comunicações, logística e até mesmo na participação de operações conjuntas com as forças policiais. Nas operações de natureza policial e de vigilância das fronteiras, portos e aeroportos, sobretudo no que diz respeito ao controle do tráfico de drogas e de armas, previa-se a concessão de "poder de polícia” e equipamento adequado para os militares. O documento reconhecia o poder militar dissuasório, com capacidade de mobilização e de resposta eficaz, como importante instrumento da estratégia brasileira de defesa nacional em relação a eventuais ameaças. Estabelecia como regiões prioritárias da defesa a Amazônia, o Atlântico Sul e os corredores aéreos. Sem embargo, o foco permanecia na proteção da Amazônia, onde se percebiam ameaças irregulares potenciais, como o extravasamento da guerrilha de países vizinhos até a criminalidade organizada.

Na campanha à reeleição presidencial de Lula em 2006, o PT, depois de duas eleições seguidas sem reservar uma seção exclusiva de seu programa de governo para a defesa nacional, voltou a fazê-lo. Porém, a seção era estritamente simples, sendo composta apenas de cinco propostas em forma de tópicos, a saber: i) concluir o processo de institucionalização do Ministério da Defesa; ii) acelerar o processo de reaparelhamento das Forças Armadas, com atenção especial aos programas estratégicos; iii) reconstruir a indústria bélica nacional, de forma articulada com os países da América do Sul; iv) dar continuidade às ações de vigilância e proteção do território nacional, sobretudo de regiões de fronteira, por meio de instrumentos como o SIVAM-SIPAM (Sistema de Proteção da Amazônia) e outros mecanismos de controle do crime organizado e de grupos que atentam contra a inte- 
gridade do território nacional; e v) acentuar a cooperação internacional em missões de paz e de intervenção no enfrentamento de catástrofes e de graves crises (PT 2006).

A primeira conclusão a que se chega com a análise dos programas de governo do PT e do PSDB entre 1994 e 2006 é a pouca ou nenhuma importância que ambos os partidos concederam aos assuntos de defesa nacional, sobretudo se comparado com outras políticas públicas. Com efeito, dos oito programas de governo elaborados no período, três deles, ou seja, quase a metade, não possuíam uma seção exclusiva para a defesa nacional (PT: 1998, 2002. PSDB: 1994). Aqueles que a possuíam apresentavam, em grande medida, propostas bastante superficiais e pouco detalhadas. Mesmo assim, o exame do conteúdo das propostas de ambos os partidos revela que as semelhanças entre eles superam as divergências. Assim, apesar da pouca densidade dos respectivos programas de governo, em matéria de defesa, o consenso predomina. De fato, tanto o PT quanto o PSDB parecem estar de acordo, como já era de se esperar, que a proteção da soberania, do território e das fronteiras nacionais corresponde ao principal objetivo da política de defesa nacional. Os partidos também coincidem: i) na identificação da Amazônia como prioridade estratégica; ii) na percepção de ameaças difusas ao território brasileiro, especialmente o tráfico de drogas, muito embora pareça haver uma diferença de ênfase no tratamento desta questão, a qual está mais presente nos programas do PSDB; iii) no fomento da participação das Forças Armadas brasileiras nas missões de paz e mediação de conflitos internacionais sob o auspício das Nações Unidas; iv) no fortalecimento da democracia com a subordinação dos militares ao poder civil por meio de iniciativas como a criação e depois consolidação do Ministério da Defesa; iv) no papel subsidiário das Forças Armadas na prestação de serviços sociais, sobretudo nas regiões de difícil acesso; v) na capacitação do poder dissuasório como instrumento de defesa do Brasil; vi) no reconhecimento da importância e necessidade do reaparelhamento, modernização e valorização das Forças Armadas; e vii) no estímulo à cooperação regional em matéria de defesa.

Notam-se diferenças partidárias um pouco mais pronunciadas em duas questões específicas. A primeira diz respeito ao emprego dos militares nas operações de garantia da lei e da ordem, as chamadas GLO. Nos programas de governo do PSDB, essa questão não só aparece com mais frequência como também as propostas a ela relacionadas são mais incisivas. Como visto acima, em 2006, o candidato tucano Geraldo Alckmin previa a concessão de "poder de polícia” e equipamento adequado para os militares quando estes fossem empregados em operações policiais. Em contraste, em nenhum dos programas de governo do PT aqui analisados observou-se alguma 
referência ao emprego das Forças Armadas em operações de GLO. Pelo contrário: no programa de 1994, propunha-se a remoção, da Constituição Federal, das atribuições conferidas aos militares na manutenção da ordem interna. A segunda questão em que o PT pareceu diferenciar-se do PSDB, em matéria de defesa, foi a referência, na campanha de 1994, às assimetrias de poder no eixo norte-sul como uma das principais fontes de tensão do sistema internacional contemporâneo. Por fim, há também algumas diferenças de ênfase entre os programas de governo do PSDB e do PT, como já dito anteriormente. Se, nas propostas tucanas, a ênfase no combate ao narcotráfico parece ser maior, nas propostas petistas ganha destaque o fortalecimento da indústria nacional de defesa e a promoção da autonomia estratégica.

\section{CONSIDERAÇÕES FINAIS}

O presente trabalho buscou examinar a natureza da política de defesa do Brasil, tentando responder se esta é uma política de Estado ou de governo. $\mathrm{O}$ debate na literatura indica que a permanência dos objetivos no longo prazo, o predomínio da continuidade frente às rivalidades domésticas e mudanças de governo e o consenso na sociedade civil em torno dos objetivos, ameaças e recursos da política de defesa são variáveis que a definiriam como uma política de Estado. Por outro lado, a ocorrência de oscilações de conteúdo e de escopo devido às disputas políticas domésticas e mudanças de governo é vista como atributo natural da política de defesa enquanto política pública e, portanto, de governo. Assim, para saber se a política de defesa constitui uma política de Estado ou de governo, foram empreendidas duas comparações: na primeira, foram cotejadas as políticas de defesa nacional dos governos Cardoso (1995-2002) e Lula (2003-2010), com o intuito de identificar os elementos de continuidade e mudança no período em exame; a segunda comparação foi feita entre as principais ideias em matéria de defesa nacional presentes nos programas de governo do PT e do PSDB entre 1994 e 2006, buscando-se aferir se existiu consenso ou predominaram divergências entre estes partidos, e se as convergências e divergências partidárias nesse período coincidiram com as continuidades e mudanças identificadas na política de defesa nacional do governo Lula em comparação à administração Cardoso. Como parâmetro de comparação, utilizaram-se algumas das dimensões essenciais da política de defesa definidas por Rudzit e Nogami (2010), a saber: interesses nacionais, fontes de ameaças, objetivos e estratégia de defesa.

As duas comparações permitem concluir que, no tocante à política de defesa brasileira, houve mais continuidade do que mudança com a alter- 
nância dos governos Cardoso e Lula. Isso porque os elementos essenciais dessa política se mantiveram os mesmos no período em estudo. Com efeito, a Amazônia e o Atlântico Sul permaneceram os espaços geográficos de prioridade estratégica para os interesses nacionais brasileiros. Em nenhum momento houve a definição precisa de inimigos, estatais ou não-estatais, a serem combatidos pelas Forças Armadas brasileiras. A prioridade da política de defesa sempre recaiu sobre as ameaças de natureza externa, muito embora, em ambos os governos, as Forças Armadas tenham sido empregadas para a provisão de segurança pública. Os objetivos principais da defesa nacional perduraram, a despeito das diferenças de ênfase na forma como estes foram perseguidos pelos diferentes governos. Finalmente, a estratégia brasileira de defesa permaneceu ancorada em premissas como a negação da guerra da conquista, preconizando a atuação diplomática e a capacitação do poder militar dissuasório como instrumentos de defesa. No que diz respeito à comparação entre os programas partidários de governo, os resultados da pesquisa mostraram que existem mais convergências do que divergências, sugerindo uma espécie de consenso interpartidário, ainda que por omissão, já que se percebeu uma falta de interesse generalizada de PT e PSDB pelos temas de defesa.

A princípio, essa conclusão parece concordar com o argumento daqueles que dizem ser a política de defesa uma política de Estado. Entretanto, os resultados da pesquisa também mostram que, a despeito da continuidade de elementos essenciais da política de defesa, houve mudanças importantes no período estudado. É certo que nem todas essas mudanças podem ser associadas diretamente à orientação ideológica do PT explanada na segunda seção do artigo. De fato, a identificação da ameaça potencial representada pela guerra cibernética, bem como a proposição de objetivos para o combate ao terrorismo, estão relacionados com as injunções peculiares da conjuntura internacional da época. Todavia, a identificação das assimetrias de poder entre as nações como fonte potencial de ameaça e instabilidade internacional e a ênfase na autonomia estratégica por meio do maior intervencionismo estatal no fomento da indústria bélica nacional coincidem bastante com alguns pontos defendidos nos programas de governo petistas ao longo dos anos.

Nos assuntos em que a defesa e a diplomacia se aproximam, a influência do pensamento petista é ainda mais pronunciada, constituindo evidências nesse sentido a ampliação do entorno estratégico em direção à África Ocidental; a maior cooperação internacional em matéria de defesa com os países em desenvolvimento e, em especial, africanos; bem como o uso da integração, sobretudo do CDS, como instrumento de contenção da unipolaridade estadunidense, embora, nesse último caso, em muito tenha 
contribuído o unilateralismo da política externa dos EUA na virada do século XX. Portanto, os resultados da pesquisa igualmente secundam os argumentos de que a política de defesa é uma política de governo. Em outras palavras, a política de defesa brasileira é uma política de Estado, mas é também uma política de governo.

\section{REFERÊNCIAS}

Abdul-Hak, A. P. N. T. 2013. O Conselho de Defesa Sul-Americano (CDS): Objetivos e interesses do Brasil. Brasília: FUNAG.

Almeida, Carlos Wellington de. 2010. "Política de defesa no Brasil: considerações do ponto de vista das políticas públicas”. Opinião Pública 16, no. 1 (Jun.), 220-250, Campinas.

Alsina Jr., João Paulo Soares. 2003. "A síntese imperfeita: articulação entre política externa e política de defesa na era Cardoso". Revista Brasileira de Política Internacional 46, no. 2, 53-86, Brasília.

2009. Política externa e poder militar no Brasil: universos paralelos. Rio de Janeiro: Editora FGV.

Bertonha, João Fábio. 2010. "Adquisiciones de armamentos y reequilibrios geopolíticos: América del Sur en la primera década del siglo XXI”. Relaciones Internacionales 39, no. 39, 109-127.

2013. "A Estratégia Nacional de Defesa do Brasil e a dos outros BRICs em perspectiva comparada”. Revista Brasileira de Política Internacional 56, no. 2, 112130, Brasília.

Boreli; P. C., and A. E. Peron. 2017. "Defesa e Desenvolvimento no Governo Lula: Uma Convergência Possível?” Revista Escola de Guerra Naval 23, no. 2, 481-510, Rio de Janeiro.

Brasil. 1996a. Política de Defesa Nacional. Governo Fernando Henrique Cardoso. Brasília: Biblioteca da Presidência.

1996b. Plano Plurianual 1996-1999. Mensagem ao Congresso Nacional. Brasília: Ministério do Planejamento - MPOG.

1996c. Mensagem ao Congresso Nacional: abertura da $2^{\text {a }}$ Sessão Legislativa Ordinária da $50^{\mathrm{a}}$ Legislatura / Fernando Henrique Cardoso. - Brasília: Presidência da República, Secretaria de Comunicação Social. 
1998. Mensagem ao Congresso Nacional: abertura da $4{ }^{\mathbf{a}}$ Sessão Legislativa Ordinária da $50^{\mathbf{a}}$ Legislatura / Fernando Henrique Cardoso. Brasília: Presidência da República, Secretaria de Comunicação Social.

- MPOG.

2000a. Plano Plurianual 2000-2003. Brasília: Ministério do Planejamento

200ob. Mensagem ao Congresso Nacional: abertura da $2^{\text {a }}$ Sessão Legislativa Ordinária da $51^{\mathrm{a}}$ Legislatura / Fernando Henrique Cardoso. Brasília: Presidência da República, Secretaria de Comunicação Social.

2001. Mensagem ao Congresso Nacional: abertura da $3^{\mathrm{a}}$ Sessão Legislativa Ordinária da $51^{\mathrm{a}}$ Legislatura / Fernando Henrique Cardoso. - Brasília: Presidência da República, Secretaria de Comunicação Social.

2002. Mensagem ao Congresso Nacional: abertura da $8^{\text {a }}$ Sessão Legislativa Ordinária da $51^{a}$ Legislatura/Fernando Henrique Cardoso. Brasília: Presidência da República, Secretaria de Comunicação de Governo e Gestão Estratégica.

. 2008. Ministério da Defesa. Estratégia Nacional de Defesa. Disponível em: <https://www.defesa.gov.br/eventos_temporarios/2009/estrategia/arquivos/ estrategia_defesa_nacional_portugues.pdf>

2005. Decreto $n^{0}$ 5.484, de 30 de Junho de 2005: Aprova a Política de Defesa Nacional, e dá outras providências. Brasília; Presidência da República Casa Civil. Subchefia para Assuntos Jurídicos.

2008a. Decreto $n^{\circ}$ 6.703, de 18 de Dezembro de 2008: Aprova a Estratégia Nacional de Defesa, e dá outras providências. Brasília; Presidência da República Casa Civil. Subchefia para Assuntos Jurídicos.

- MPOG;

2008b Plano Plurianual 2008-2011. Brasília: Ministério do Planejamento

Camino, E. M. B., and J. T. M. Menck. 2016. O Centro de Lançamento de Alcântara versus a tramitação legislativa da mensagem $n^{\circ}$ 296, de 2001, do Poder Executivo (TSA com os Estados Unidos). In: Estudo Técnico. Consultoria legislativa - Câmara dos Deputados.

Cardoso, Fernando Henrique. 2008a. Mãos à obra, Brasil: proposta de governo. Rio de Janeiro: Centro Edelstein de Pesquisa Social. 131 p.

. 2008b. Avança Brasil: proposta de governo. Rio de Janeiro: Centro Edelstein de Pesquisa Social. 172p. 
Correa Filho, Sérgio Leite Schmitt et. al. 2013. "Panorama sobre a indústria de defesa e segurança no Brasil”. BNDES Setorial. Rio de Janeiro, no. 38, 373-408.

Hurrel, Andrew. 2006. "Hegemony, liberalism and global order: what space for would-be great powers?” International Affairs 82, no, 1, 1-19.

Lima, Raphael Camargo. 2015. A Articulação entre Política Externa e Política de Defesa no Brasil: Uma Grande Estratégia Inconclusa. Dissertação (Mestrado em Relações Internacionais pelo Programa de Pós-Graduação "San Tiago Dantas" Unesp, Unicamp, PUC-SP). São Paulo.

Martins Filho, João Roberto. 2000. "O governo Fernando Henrique e as Forças Armadas: um passo à frente, dois passos atrás”. Revista Olhar 2, no. 4, Campinas.

Oliveira, Eliézer Rizzo de. 2006. “Considerações políticas sobre a Defesa Nacional”. Com Ciência - Revista Eletrônica de Jornalismo Científico, SBPC.

Proença Jr., Domício; and Erico Duarte. 2003. “Comentários a uma nova Política de Defesa Brasileira”. Security and Defense Studies Review 3, 164-192.

PSDB. 2002. Trabalho e Progresso para Todos. Programa do Governo José Serra.

PSDB. 2006. Geraldo Alckmin Presidente. Programa de Governo.

PT. 1994. Lula, presidente: uma Revolução Democrática no Brasil. Bases do Programa de Governo. 1998. União do Povo - Muda Brasil. Diretrizes do Programa de Governo.

Presidente.

2002. Um Brasil para Todos. Programa de Governo. Coligação Lula 2006. Lula de novo com a Força do Povo. Lula Presidente Programa de Governo.

Rudzit, Gunther, and G. S. P. Casarões. 2015. "Política de Defesa é uma Política de Governo". Revista Brasileira de Estudos de Defesa 2, no. 1, 33-52.

Rudzit, Gunther, and Otto Nogami. 2010. "Segurança e Defesa Nacionais: conceitos básicos para uma análise". Revista Brasileira de Política Internacional 53, no. 1, 5-24, Brasília.

Saint-Pierre, H. C., and E. C. Winand. 2003. "A questão da Defesa e as Forças Armadas brasileiras nos primeiros meses do governo Lula”. Estúdios PolíticoMilitares 3, no. 5, 107-126, Centro de Estudios Estratégicos - Universidad Arcis, 
Teixeira Júnior, A. W. M. 2013. O Brasil e a Criação do Conselho de Defesa SulAmericano da Unasul: Cooperação e Balanceamento como Estratégias de Autoajuda. Tese de Doutorado em Ciência Política (Departamento de Ciência Política da Universidade Federal de Pernambuco (UFPE)), Recife.

Teixeira Júnior; A. W. M., and A. H. Silva. 2017. "Explaining Defense Cooperation With Process-tracing: the Brazilian Proposal for the Creation of UNASUR South American Defense Council”. Revista Brasileira de Política Internacional 60, no. 2, 1-18, Brasília.

Vaz, Alcides Costa. 2013. "A Ação Regional Brasileira sob as Ópticas da Diplomacia e da Defesa: Continuidades e Convergências". In: SORJ, Bernardo; FAUSTO, Sergio (ORGs.). O Brasil e a Governança da América Latina: Que Tipo de Liderança é Possível? São Paulo: Fundação iFHC/Centro Edelstein. Capítulo VII, p. 233-266. 


\section{NOTAS}

1. Apesar de a PDN de 1996 e 2005 mencionar a contribuição do Brasil nas missões de manutenção da paz como objetivo de sua política de defesa, a participação brasileira na Missão das Nações Unidas para a estabilização no Haiti (MINUSTAH) certamente constitui uma inovação importante do governo Lula, sobretudo porque tal missão foi embasada no capítulo VII da Carta das Nações Unidas, capítulo este ao que a diplomacia brasileira historicamente se mostrou contrária como fundamento jurídico de operações internacionais de paz. Esta foi a razão pela qual o país não participou das missões de paz que ocorreram anteriormente no Haiti, como aquela promovida em 1994.

2. Ao final da administração Cardoso, as Forças Armadas brasileiras encontravam-se em situação de penúria, de acordo com alguns jornais da época. Em 2002, em função dos contingenciamentos orçamentários, 44 mil recrutas teriam sido dispensados do Exército, e o desfile de comemoração pelo dia da Independência não pôde contar com o passeio de veículos militares nem com o sobrevoo dos caças por falta de combustível. De igual modo, porta-aviões e destroieres da Marinha tiveram de ser desativados. Na Aeronáutica, cerca de $45 \%$ dos aviões da Força Aérea Brasileira (FAB) não satisfaziam as condições mínimas de vôo (Saint-Pierre and Winand 2003).

3. Dados extraídos do IISS. The Military Balance. Séries 1995 a 2010.

4. O governo do presidente Fernando Henrique Cardoso também teve participação importante no envio de tropas brasileiras para missões de paz da ONU, especialmente a UNAVEM III (United Nations Angola Verification Mission), que durou entre 1995 e 1997, e na qual o Brasil chegou a comprometer mais de mil tropas por mês (em 1997, o Brasil figurou entre os quatros países que mais contribuíam com tropas para as missões de manutenção de paz da ONU). Ainda assim, a participação brasileira na MINUSTAH se sobressai, dado o elevado contingente de tropas aportado pelo Brasil, combinado ao amplo período de tempo em que o país esteve à frente da missão.

5. Os incentivos jurídicos, fiscais e financeiros à indústria bélica nacional foram contemplados pela Política Nacional da Indústria de Defesa (PNID) de 2005 e também pela Política de Desenvolvimento Produtivo, lançada em 2008 (Correa Filho et.al. 2013; Boreli and Peron 2017).

6. Conforme os dados compilados por Lima (2015), durante seu governo, Cardoso firmou, ao todo, 14 acordos internacionais em matéria de defesa, ao passo que Lula, 47. Dos 14 acordos firmados por Cardoso, seis foram com países avançados e oito, isto é, uma pequena maioria, com países em desenvolvimento. Entre os países em desenvolvimento, 
não havia nenhum africano. Dos 47 acordos em matéria de defesa assinados no governo Lula, apenas 14 foram com países avançados, sendo os 33 restantes com países em desenvolvimento. Entre estes, 11 eram africanos.

7. Para uma análise dos objetivos do CDS do ponto de vista da política externa brasileira, ver também Abdul-Hak (2013) e Teixeira Júnior (2013). 


\section{RESUMO}

O objetivo do artigo consiste em avaliar a natureza da política de defesa nacional do Brasil enquanto política pública. Mais especificamente, busca-se responder à seguinte questão: a política de defesa nacional do Brasil constitui uma política de Estado, cuja orientação é definida preponderantemente por condicionantes sistêmicos, uma vez que goza de amplo consenso entre as forças políticas no plano doméstico? Ou uma política de governo, sobre a qual incidem as injunções conjunturais de natureza partidário-ideológica, estando sujeita, pois, a oscilações de conteúdo e escopo conforme ocorram mudanças nas coalizões de governo? Para responder essa pergunta, o artigo realiza duas comparações. Na primeira, são cotejadas as políticas de defesa nacional dos governos Cardoso (1995-2002) e Lula (2003-2010), com o intuito de identificar os elementos de continuidade e mudança no período em exame. A segunda comparação é feita entre as principais ideias em matéria de defesa nacional presentes nos programas de governo do PT e do PSDB entre 1994 e 2006. Com essa comparação, busca-se aferir se existe consenso ou predominam divergências entre estes partidos, e se as convergências e divergências partidárias coincidem com as continuidades e mudanças identificadas na política de defesa nacional do governo Lula em comparação à administração Cardoso. Os resultados da pesquisa apontam que, entre 1995 e 2010, a política de defesa nacional do Brasil apresentou características de política de Estado, dada a continuidade no tempo de seus principais interesses e objetivos, mas também de política de governo, com a percepção de novas ameaças, a introdução de inovações conceituais e mudanças de ênfase associadas à orientação ideológico-partidária do governo Lula.

Palavras-chave: Defesa Nacional; Política de Defesa; Política de Estado; Política de governo.

\section{ABSTRACT}

The purpose of this article is to evaluate the nature of Brazil's national defense policy as a public policy. More specifically, it seeks to answer the following question: Brazil's national defense policy is a State policy, whose orientation is defined predominantly by systemic constraints, since it enjoys a broad consensus among the political forces at the domestic 
level, or a government policy, on which act the conjunctural injunctions of a partisan-ideological nature, and are therefore subject to oscillations of content and scope as changes in government coalitions occur? To answer this question, the article makes two comparisons. In the first one, the national defense policies of the governments Cardoso (1995-2002) and Lula (2003-2010) are checked, in order to identify the elements of continuity and change in the period under review. The second comparison is made between the main ideas on national defense present in the government programs of the PT and PSDB between 1994 and 2006. With this comparison, it is sought to gauge if there is a consensus or predominate divergences between these parties and if the convergences and party divergences coincide with the continuities and changes identified in Lula's national defense policy in comparison to the Cardoso administration. The results of the research indicate that, between 1995 and 2010, Brazil's national defense policy presented characteristics of State policy, given the continuity in time of its main interests and objectives, but also of government policy, with the perception of new threats, the introduction of conceptual innovations and changes of emphasis associated with the ideological/partisan orientation of the Lula government.

Keywords: National Defense; Defense Policy; State Policy; Government Policy. 